reflexes and the tonic vibration reflex were measured by the methods previously described ${ }^{1}$ while the patients were on their maximum therapeutic dose of levodopa. Bromocriptine was then substituted and the maximum therapeutic dose established (20-50 mg daily), the measurements being repeated after two weeks' treatment with this dose. Finally the original dose of levodopa was restored bromocriptine withdrawn, and a third set of meas urements made. No significant reflex changes occurred, suggesting that levodopa and bromocrip tine share a similar spectrum of activity in this respect.

The clinical effects of bromocriptine resembled those described in larger series. ${ }^{4}$ The three patients who had not responded at all to levodopa did no respond to bromocriptine. The three who had troublesome end-of-dose akinesia reported longer and more predictable release periods with bromocriptine, provided they took it every two to three hours; two took small doses of Sinemet twice daily in addition. One of these patients has subsequently developed postural hypotension, the symptoms of which are relieved by wearing elastic stockings. The seventh patient maintained a partial response with bromocriptine but experienced the same side effect, confusion, as with Sinemet and has preferred to stay on his former treatment.

These observations fail to support the hypothesis that bromocriptine has a more specific effect than levodopa in Parkinsonism. Never theless, bromocriptine is a useful addition to current remedies.

I thank The London Hospital and Ciba-Geig Laboratories for financial support. Bromocriptine was supplied by Sandoz Products Ltd.

\section{L MCLELLAN}

Department of Neurology

The London Hospital (Whitechapel),
London E1

McLellan, D L, fournal of Neurology, Neurosurger and Psychiatry, 1973, 36, 342. Baker, $\mathrm{R} \mathrm{G}$, and Anderson, $\mathrm{E} \mathrm{G}$, fournal of Pharmat-
cology and Experimental Therapeutics, i970, 173,

212 and 224.
Andrews, C J, Australian and New Zealand fournal

- Calne, D B, et al, British Medical fournal, 1974, 4, 442.

- Parkes, J D, et al, fournal of Neurold

'McLellan, D L, et al, Acta Neurologica Scandinavica,
1975, 51, 74.

\section{Dietary fibre}

SIR,-I would like to add some comments to the answer given by your expert to the question "What is the most effective source of fibre in the diet and how much should be taken?" (12 June, $\mathrm{p}$ 1461).

I agree with the comment that "fibre" is a mental shorthand for a mixture of components and that we do not know which of these is important. It is, however, possible to say a little more about the complex polysaccharides that can be regarded as "dietary fibre" in bran. Bran does not have a constant composition and the amounts of dietary fibre that it contains will depend on its method of production, and specifically on the amount of associated endosperm. The starch in this endosperm will dilute the dietary fibre, and a bran prepared by sieving wholemeal flour may contain more starch and less dietary fibre than a bran separated earlier in the milling process.

Subject to the above I think that better values for a typical bran are as follows: crude fibre (approximately equivalent to cellulose plus lignin), 9-12 g/100 g; and total dietary fibre, $36-46 \mathrm{~g} / 100 \mathrm{~g}$. Bran dietary fibre therefore contains $60-75 \%$ of the total as noncellulosic polysaccharides (hemicelluloses, etc) of which arabinoxylans constitute a major pro- portion. Brans of this type usually contain about $22-27 \mathrm{~g} / 100 \mathrm{~g}$ of starch. Wholemeal breakfast cereals contain approximately $12 \mathrm{~g}$ / $100 \mathrm{~g}$ total dietary fibre, and a preparation such as All-Bran about $27 \mathrm{~g} / 100 \mathrm{~g}$. Almost al breakfast cereals contain some maltose and in none of these are the amounts likely to have any laxative effect.

My colleagues and I have analysed a range of typical foodstuffs and have produced from this a guide to calculating dietary fibre that has recently been accepted for publication."

\section{A T Southgate}

Dunn Nutritional Laboratory,

Cambridge

1 Trowell, H, et al, Lancet, 1976, 1, 967. In press.

***Our expert writes: "I was most interested to read Dr Southgate's letter and pleased that we shall at last have a table of foodstuffs with their calculated dietary fibre contents. His contribution to nutritional research is already outstanding. Inadvertently he has drawn a red herring across the original question, which was on the construction of high-residue diets. Specifically All-Bran is clearly not all bran and in the context in which it was being discussed it was not being used as a breakfast cereal but as a therapeutic addition to diet. Notwithstanding Dr Southgate's assurances, malt is an excellent laxative and All-Bran seems to produce more liquid stools than plain bran supplements."-ED, BMF.

\section{Cutaneous bullae and frusemide in} chronic renal failure

SIR,-We read with great interest the article by Professor A C Kennedy and Dr A Lyel (19 June, p 1509) describing seven patients with cutaneous bullae and chronic renai failure. However, Gilchrest et al ${ }^{1}$ from America, Korting," from West Germany, and Burry and Lawrence: ${ }^{3}$ from Australia have also described five, two, and four similar cases respectively. In addition, we have reported five other cases ${ }^{4}$ and agree that the cutaneous bullae appear to be associated with chronic renal failure, frusemide therapy, and exposure to sunlight but not with porphyria.

One of our five patients has again developed bullous lesions on her hands this summer during the recent sustained sunny weather. She has a year-old renal transplant with a creatinine clearance of $33 \mathrm{ml} / \mathrm{min}$ and is taking frusemide $40 \mathrm{mg}$ daily, prednisolone $14 \mathrm{mg}$ daily, and azathioprine $50 \mathrm{mg}$ twice daily. It is possible that her extensive lesions are the result of a phototoxic reaction to frusemide and impaired renal function. To date one other patient has died and the recurrence of the lesions has not been recorded in the remaining three patients.

We are unaware of any report of seasonal recurrence of these cutaneous bullae.

K KECZKES

Departments of Dermatology and

$M$ J FARR Nephrology, Hull

${ }^{1}$ Gilchrest, B, Rowe, J W, and Martin, C, Annals of Internal Medicine, 1975, 83, 480 Internal Medicine, 1975, 83, 480. $150,58$. ${ }^{3}$ Burry, J N, and Lawrence, J R, British fournal of

Keczkes, K, and Farr, M J, British fournal of Dermatology. In press.

\section{Requests for references}

SIR,-I wonder whether others besides myself are becoming concerned about the increasingly slack manner in which many health authorities in the United Kingdom are making requests for references for medical appointments at all levels.

There was a time when such a request took the form of a polite, individually prepared letter from a medical colleague in the specialist department concerned or one signed by a medical administrator. Nowadays, even for consultant appointments, they often arrive in the form of a scruffy circular over the indecipherable cyclostyled signature of someone described as "personnel officer," and I have even received one subscribed by the ultimate insult of an indecipherable cyclostyled "per pro" signature.

The security accorded to references is also often in grave doubt. It may be that the ethics of sending references about the work of a medical colleague to a non-medical administrator must be reluctantly accepted, but the propriety of despatching it in the envelope provided by some health authorities is palpably suspect; this may not be addressed to a named or designated officer and is frequently not even marked "in confidence." Sometimes, too, the request arrives at the last moment in a second class envelope and the referee is compelled to resort to the telephone if he has the interest of his candidate at heart.

There are still some health authorities which ask for references in a courteous and confidential manner. I am always happy to oblige them but, in general, requests for references from NHS authorities compare unfavourably with the increasing number received from medical institutions in North America, Australia, and elsewhere overseas.

Royal Berkshire Hospital,

T B BoultoN Reading

\section{Misleading statistics}

SIR,-I have only belatedly received and read your leading article (7 February, p 303) on misleading statistics and would wholeheartedly agree with your emphasis on the dangers of highly significant statistical correlations that may erroneously point to causal relations.

However, you then suggest that environmental causes of disease may be determined by the demonstration of differences in incidence of disease and relating them to similar variations of the causal factors. This may also lead to false associations. Travelling in one of our high Himalayan valleys the other day one noticed the profusion of wild white roses. The villagers will tell you that these cause diarrhoea-not by taking them, but merely by their presence. The high incidence of diarrhoea at this time of year is a fact, as also the white roses, but there is no logical connection between the two.

This surely is the lesson from John Snow's classical epidemiological investigations, that it is not enough to find significant associations, but the hypothesis must include a logical connection between cause and effect.

J S BERKELEY

General Hospital,

Thimphu,
Bhutan 